\title{
Evaluación de los sistemas de cultivo semisólido y BIT en la multiplicación in vitro de Juglans neotrópica
}

\author{
Mélida N. Rocano, Paulina G. Villena, Denisse F. Peña \\ Carrera de Ingeniería Agronómica, Facultad de Ciencias Agropecuarias, Universidad de Cuenca, \\ Avenida 12 de Octubre y Diego de Tapia, Cuenca, Ecuador. \\ Autor de correspondencia: denisse.pena@ucuenca.edu.ec \\ Fecha de recepción: 20 de mayo 2017 - Fecha de aceptación: 9 de junio 2017
}

\section{RESUMEN}

El propósito de este estudio fue evaluar el efecto de dos sistemas de cultivo, semisólido e inmersión temporal en biorreactor (BIT), para la multiplicación in vitro de Juglans neotrópica, a partir de embriones cigóticos. En el sistema BIT se analizó también el efecto de la frecuencia de inmersión y la ventilación artificial. El desarrollo de los brotes obtenidos fue evaluado sobre las siguientes características: número y tamaño de los brotes, número de hojas, peso fresco y seco. No se encontraron diferencias estadísticamente significativas. En general, el sistema de inmersión BIT produjo un número de brotes equivalente, con características similares a los obtenidos en el método convencional en medio semisólido. Sin embargo, los BITs produjeron más brotes, la ventilación forzada redujo el número de brotes hiperhídricos y el sistema BIT fue considerablemente más barato, con un costo medio de producción de $\$ 0.21$ por planta versus $\$ 0.40$ en el método de propagación en cultivo semisólido.

Palabras clave: Juglans neotrópica, Bioreactores de Inmersión Temporal (BIT), nogal.

\begin{abstract}
The purpose of this study was to evaluate two culture systems, semi-solid and temporary immersion in bioreactors (BIT), for the micropropagation of Juglans neotropica, using zygotic embryos. Additionally, in the BIT culture system also the effect of the frequency of immersion and forced aeration on the micropropagation was examined. The culture growth of the shoots was measured by the following characteristics: number and size of the shoots, number of leaves, and the wet and dry weight. No statistical differences were detected. In general, the BIT immersion system produced an equivalent number of plants of similar characteristics as the embryos propagated in the traditional semi-solid medium method. However, BITs produced more shoots, forced ventilation resulted in less hyperhydric shoots and the BIT system was considerable cheaper, resulting in an average production cost of $\$ 0.21$ per plant versus $\$ 0.40$ in the semi-solid propagation method.
\end{abstract}

Keywords: Juglans neotropica, Temporary Immersion Bioreactors (BIT), Andean walnut.

\section{INTRODUCCIÓN}

El nogal, Juglans neotrópica, es una especie nativa de Ecuador, Colombia, Perú y Bolivia (Rojas \& Torres, 2008). Por su gran capacidad adaptativa es recomendada en programas de forestación y reforestación de ecosistemas altoandinos (Herrera, 2016). Típicamente, la propagación de J. neotrópica se realiza por semillas. No obstante, debido a su baja e irregular capacidad germinativa y latencia profunda, los porcentajes de germinación observados usando este método son muy bajos $(\sim 7 \%)$, limitando la aplicabilidad de este método para producir plántulas en número suficiente y de forma consistente para sostener programas de conservación, regeneración y aprovechamiento sostenible (López \& Piedrahita, 1998; Herrera, 2016). Por este motivo, J. neotrópica ha sido identificada como 
una especie que podría beneficiarse del desarrollo de protocolos de multiplicación in vitro a partir del cultivo de embriones.

El cultivo de embriones in vitro es una técnica que ha sido utilizada con éxito para la regeneración de plantas (Toosi \& Dilmagani, 2010) de genotipos élite, especies amenazadas y difíciles de propagar a través de otros métodos (Watt, 2012). En el caso de Juglans spp., varios protocolos de propagación in vitro han sido reportados hasta el día de hoy (Long \& Van Sambeek, 1995; Sánchez et al., 2006; Bosela \& Michler, 2008; Payghamzadeh \& Sayyed, 2011; Amiri \& Gharati, 2012; Peña et al., 2014). No obstante, estos protocolos dependen de técnicas de cultivo en medios semisólidos que requieren una importante inversión de tiempo y personal calificado para su desarrollo, lo cual limita su aplicación efectiva para dar soporte a programas que requieren producción constante de un gran número de plantas.

Los sistemas de inmersión temporal (SIT) son plataformas semi-automatizadas que permiten el contacto controlado de corto tiempo del material a propagar con un medio líquido en un ambiente aséptico (Georgiev et al., 2014). Estos sistemas poseen la ventaja (frente a los sistemas en medios semisólidos) de minimizar el tiempo dedicado a la manipulación del material y el requerimiento de personal. Además, en algunas especies, el cultivo en SITs ha mejorado también la respuesta fisiológica de las plantas, incrementando índices de multiplicación y logrando una mayor eficiencia en el cultivo (Escalona et al., 2007). Diferentes variantes de SITs han sido desarrolladas, entre ellas, el Recipiente de Inmersión Temporal Automatizado (RITA®) (Alvard et al., 1993), el Biorreactor Modular de Inmersión Temporal (BioMINT®) (Robert et al., 2005), el Biorreactor de Inmersión por Gravedad (BIG) (Ducos et al., 2007), el Biorreactor de Inmersión Temporal (BIT®) (Escalona et al., 2007), entre otros.

Los Biorreactores de Inmersión Temporal, más conocidos como BITs, están formados por dos contenedores gemelos conectados entre sí por una manguera de silicona, uno de ellos contiene los explantes y en el otro se almacena el medio de cultivo. Cada contenedor está conectado a una manguera a través de la cual se inyecta aire a presión, este aire hace que el medio de cultivo líquido sea transferido al recipiente que contiene los explantes, a través de la manguera que los interconecta. La presión de aire continua permite la aireación del contenedor y agita los explantes mientras dura el tiempo programado para la inmersión. Al finalizar el tiempo programado, se detiene la presión de aire y una nueva presión, que en esta ocasión viene desde el otro contenedor (el que contiene los explantes) hace que el medio regrese al contenedor de origen. El sistema usa un temporizador, una bomba de presión y filtros de aire para mantener la esterilidad dentro de los frascos (Vasil et al., 2014). Además, el sistema BIT permite inyectar ventilación adicional (ventilación forzada), útil para reducir la humedad, y evitar la hiperhidricidad.

El sistema BIT tiene ventajas: su simplicidad de manejo y su bajo costo, comparado con otros sistemas como el RITA® (Ramírez-Mosqueda \& Iglesias-Andreu, 2016). Asimismo, el medio de cultivo puede ser reemplazado o renovado sin causar estrés a los explantes ni arriesgar su asepsia, y los contenedores pueden ser adaptados a las necesidades y recursos disponibles. Estas ventajas nos llevaron a la selección del sistema BIT para el desarrollo del ensayo. El sistema BIT ha sido usado con éxito en especies como piña, banano, caña de azúcar y especies forestales como cacao, entre otras (RamírezMosqueda \& Iglesias-Andreu, 2016).

En este trabajo reportamos el efecto de los sistemas de cultivo: semisólido y de inmersión temporal, empleados para la multiplicación in vitro de J. neotrópica y el efecto de la frecuencia de inmersión y la ventilación forzada al usar BITs. El protocolo reportado puede ser utilizado para su propagación masiva, produciendo plantas en número y calidad equivalente o mejor a métodos reportados de cultivo en medios semisólidos.

\section{MATERIALES Y MÉTODOS}

Semillas de J. neotrópica fueron colectadas en la parroquia Tomebamba, provincia del Azuay. A partir de estas semillas se extrajeron embriones cigóticos y se desinfectaron siguiendo el protocolo descrito por Peña et al. (2014). Estos embriones fueron cultivados preliminarmente en medio Murashige \& Skoog (MS) (Murashige \& Skoog, 1962; Quintero \& Jaramillo, 2012). Posteriormente, las microplántulas obtenidas de la germinación de los embriones, que alcanzaron un tamaño entre 2.5 a 3 
$\mathrm{cm}$, con al menos 2 o 3 hojas, se usaron para establecer los ensayos. La formulación del medio de cultivo usado en todos los ensayos fue: sales DKW (Driver \& Kuniyuki, 1984) suplementadas con BAP $0.7 \mathrm{mg} \mathrm{l}^{-1}$ y $0.05 \mathrm{mg} \mathrm{l}^{-1}$ de IBA (Peña et al., 2014), previamente elaborado y esterilizado en autoclave a $120^{\circ} \mathrm{C}$ durante 20 minutos.

En el primer ensayo, se evaluó el efecto del sistema de cultivo (BIT vs. semisólido). Para el tratamiento en BIT, no se agregó agar al medio, mientras que el medio de cultivo semisólido fue suplementado con $7 \mathrm{~g} \mathrm{l}^{-1}$ de agar. Para los dos sistemas se utilizaron frascos de vidrio con una capacidad de 21 que contenían $300 \mathrm{ml}$ de medio y 10 explantes obtenidos de la germinación de los embriones previamente cultivados en medio Murashige \& Skoog (MS). Al no existir referencias de trabajos similares en J. neotrópica, un tiempo de inmersión de 2 minutos cada 6 horas fue establecido para el sistema BIT, en base a resultados reportados en trabajos con otras especies (Castro \& Gonzales, 2002; Llanos Buendía, 2015; Alvarenga Venutolo, 2015). Los frascos de ambos sistemas se mantuvieron en cuarto de cultivo con un fotoperíodo de 16 horas de luz artificial fluorescente de $42-48 \mu \mathrm{mol} \mathrm{m}^{-2} \mathrm{~s}^{-1}$ y 8 horas de obscuridad a temperatura ambiente $\left(24^{\circ} \mathrm{C} \pm 2\right)$ y humedad relativa del $60 \%$. Se empleó un diseño completo al azar de un factor (sistema de cultivo) con 2 repeticiones. Al final del ensayo, luego de 45 días, se evaluó el número de brotes obtenidos por explante, la altura, peso fresco y seco de los brotes y el número de hojas por brote individualizado. Se aplicaron pruebas U de Mann Whitney para el análisis de los datos, usando el programa SPSS 22.0.

En un segundo ensayo, tres frecuencias de inmersión, 6, 8 y 12 horas, con una duración de 2 minutos fueron evaluadas únicamente en el sistema BIT. En esta ocasión se incluyó el factor ventilación forzada, aplicada por 1 minuto cada 4 horas. El experimento se realizó con un diseño completamente al azar, con arreglo factorial de 3 (frecuencias de inmersión) x 2 (con y sin ventilación) con una repetición. Al igual que en el ensayo anterior se sembraron 10 explantes por cada frasco de 21 de capacidad que contenía $300 \mathrm{ml}$ de medio de cultivo y se mantuvieron en las mismas condiciones descritas para el primer ensayo. Después de 45 días, se evaluó el número de brotes obtenidos por explante, la altura, el peso fresco y seco de los brotes, el número de hojas por brote individualizado y el número de brotes hiperhídricos. Usando el programa SPSS 22.0 se aplicaron pruebas U de Mann Whitney para el análisis de los datos ya que éstos presentaron un comportamiento asimétrico.

\section{RESULTADOS Y DISCUSIÓN}

Se obtuvieron 1.97 ( \pm 0.17) nuevos brotes por explante en medio semisólido, mientras que en BIT se registró una media de $3.37( \pm 0.34)$ brotes. Pese a que estos resultados podrían sugerir, a simple vista, una ventaja de los BIT, éstos mostraron alta variabilidad y esta diferencia no fue estadísticamente significativa, por lo que ambos sistemas fueron equivalentes en cuanto al número de brotes producidos por explante.

Este resultado contrasta con los reportados por Ross \& Castillo (2010) quienes, empleando biorreactores, lograron incrementar la multiplicación de Achyrocline fláccida de 4 brotes en sistema semisólido a 11 brotes en BIT; Castro \& Gonzales (2002) lograron en E. grandis una tasa de multiplicación de 11.5 brotes por explante, y Alvarenga (2015) obtuvo hasta 13 brotes por explante en Stevia rebaudiana. Perugorria (2012) también afirma que el uso de medio líquido en BIT, aumentó significativamente la tasa de proliferación en manzana y eucalipto, con respecto al medio semisólido.

En cuanto a los valores registrados para las variables tamaño de brote, número de hojas, masa fresca y seca, éstos no mostraron diferencias significativas entre los dos sistemas de cultivo (Figura 1). 
MASKANA, Vol. 8, No. 1, 2017

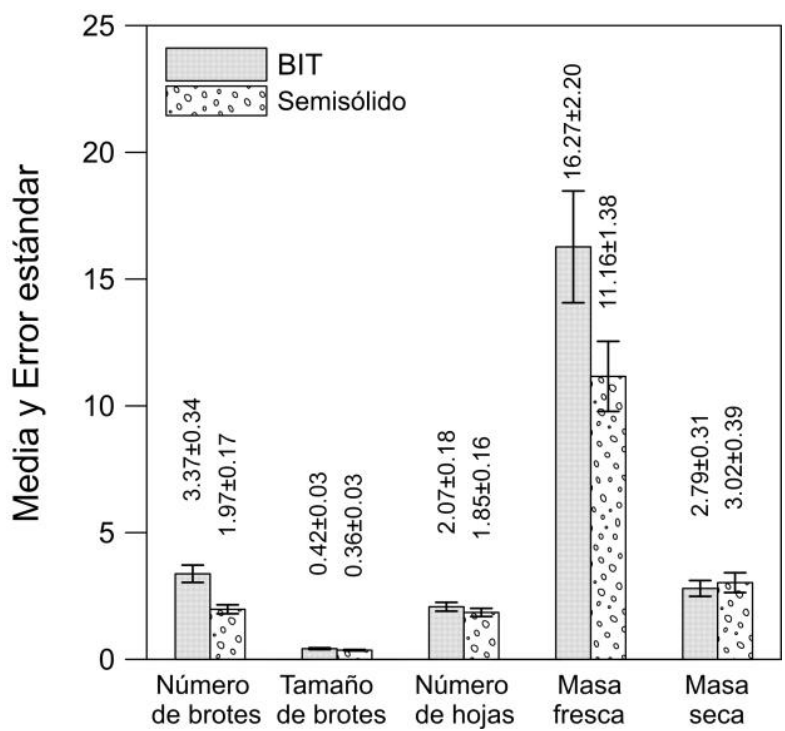

Figura 1. Variables evaluadas (número de brotes, tamaño del brote, número de hojas, masa fresca y masa seca) en los sistemas de cultivo BIT y semisólido.

En el segundo experimento, los datos obtenidos de las tres frecuencias de inmersión no presentaron diferencias significativas entre sí para las variables: número de brotes generados por explante, tamaño, número de hojas, masa fresca y masa seca de cada brote, en las tres frecuencias de inmersión evaluadas (6, 8 y 12 horas entre cada inmersión) (ver Figura 2). No obstante, la morfología general de las plantas producidas fue diferente en plantas expuestas a diferentes frecuencias de inmersión (Foto 1).

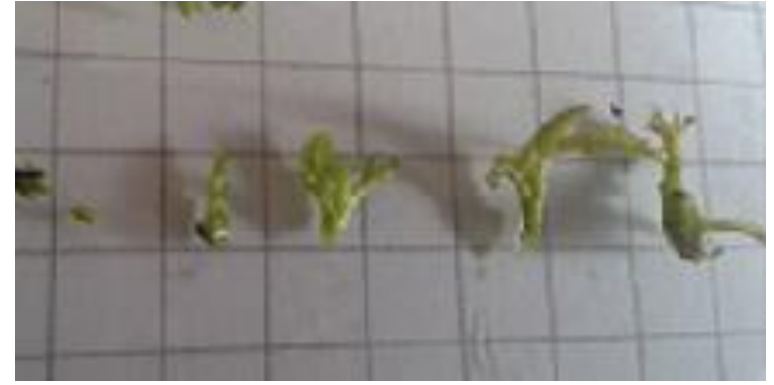

(a)

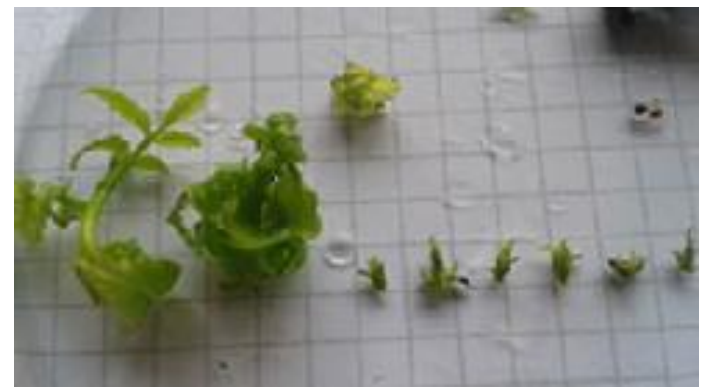

(b)

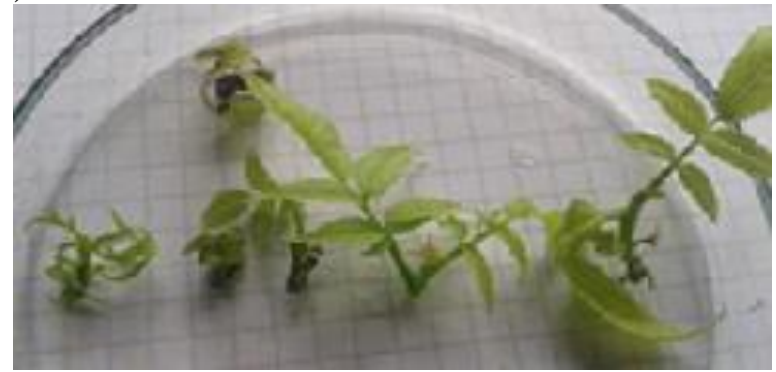

(c)

Foto 1. Brotes obtenidos en las diferentes frecuencias de inmersión: (a) cada 6 horas, (b) cada 8 horas, (c) cada 12 horas. Cuadrícula de $0.5 \mathrm{~cm}$. 

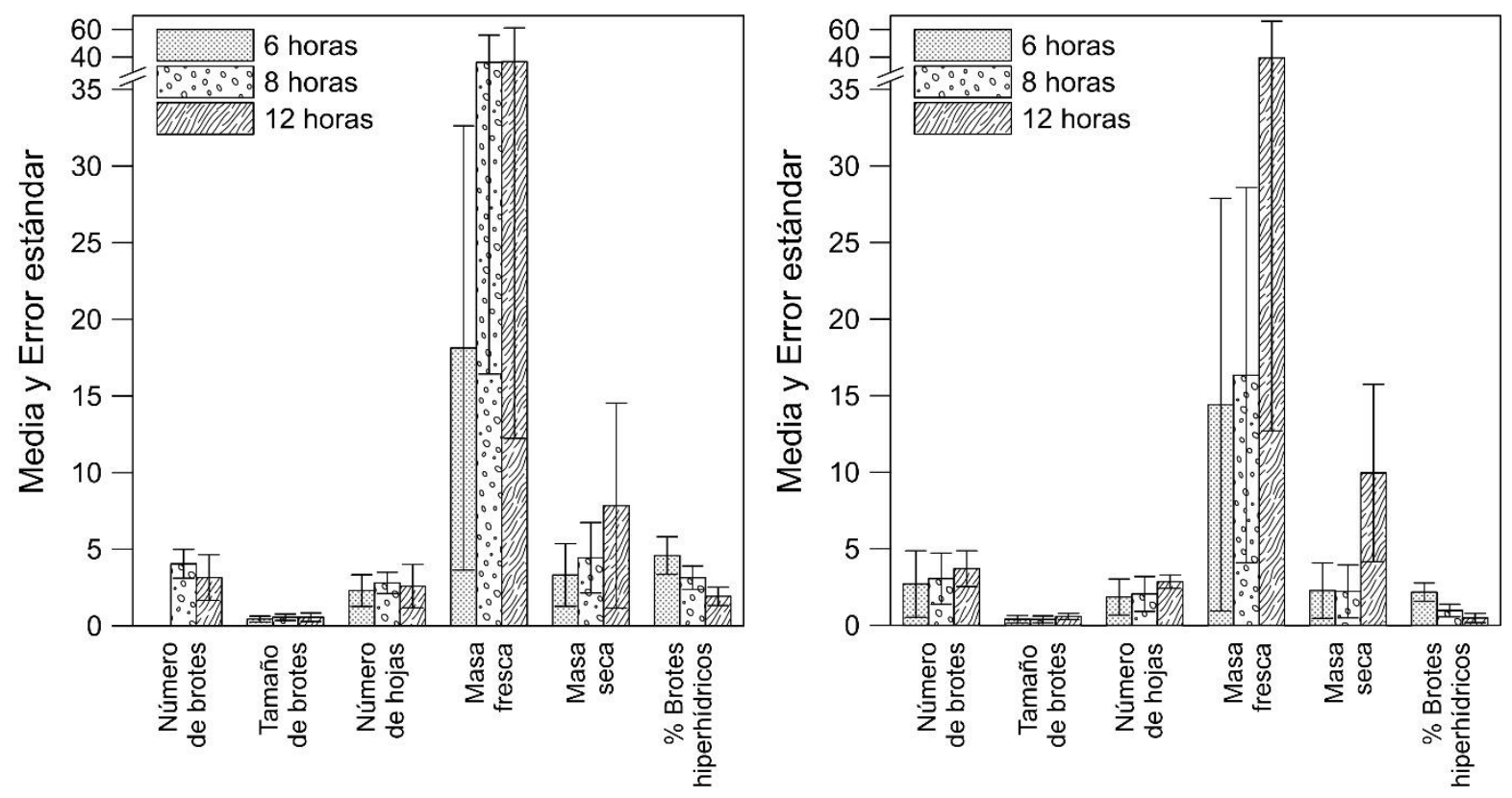

Figura 2. Variables evaluadas (número de brotes, tamaño del brote, número de hojas, masa fresca, masa seca y \% de brotes hiperhídricos) en las tres frecuencias de inmersión, sin (izquierda) y con (derecho) ventilación.

Por otra parte, cuando la ventilación forzada fue aplicada, se pudo observar una reducción en el número de brotes hiperhídricos en las tres frecuencias ensayadas, al combinar la frecuencia de inmersión cada 12 horas con la ventilación forzada la producción de brotes hiperhídricos se redujo al $0.48 \%$ (Figura 2), coincidiendo este resultado con lo reportado por De Feria Silva et al. (2003) en Psidium guajava quienes indican que la aplicación de ventilación forzada redujo la hiperhidricidad de la plántulas al renovar el ambiente interno del frasco de cultivo.

Por otra parte, al analizar los costos de producción para ambos métodos, se determinó un valor por planta de \$0.21 usando BITs y de \$0.40 usando medio semisólido. Los componentes que elevaron los costos de producción en el sistema semisólido fueron el valor de la mano de obra y el agar incluido en el medio semisólido. Consecuentemente, el uso de BITs permitió producir plantas de igual calidad que el protocolo que usa medio semisólido reduciendo costos y tiempo de trabajo.

\section{CONCLUSIÓN}

Por lo mencionado antes, la aplicación de BITs podría ser un aporte para incrementar la eficiencia de los procesos de propagación de J. neotrópica que dan soporte a programas de forestación, reforestación o aprovechamiento sostenible de esta especie, reduciendo costos de producción. Al ser este el primer reporte de multiplicación in vitro de J. neotrópica en BITs, se establece una base para el uso de esta tecnología en la propagación semiautomatizada de esta especie. Finalmente, por la gran variabilidad observada al trabajar con embriones, se sugiere la aplicación de una estrategia de selección previa del material que permita identificar las microplántulas que mejor responden a la multiplicación in vitro. 


\section{BIBLIOGRAFÍA}

Alvard D, Cote FD, Teisson C (1993). Comparison of methods of liquid medium cultures for banana micropropagation. Effect of temporary immersion of explants. Plant Cell, Tissue and Organ Culture 32:55-60

Alvarenga Venutolo S (2015). Micropropagación masiva de Stevia rebaudiana Bertoni en sistemas de inmersión temporal. Cultivos Tropicales 36(3):50-57

Amiri M, Gharati S (2012). Influence of medium composition on multiplication of walnut (Juglans regia L.) growth. Journal of Medicinal Plants Research 6(8):1482-1485

Bosela M, Michler C (2008). Media effects on black walnut (Juglans nigra L.) shoot culture growth in vitro: evaluation of multiple nutrient formulations and cytokinin types. In Vitro Cellular and Devevelopmental Biology - Plant 44:316-329

Castro D, González J (2002). Eucalyptus (Eucalyptus grandis Hill ex Maiden) micropropagation in a temporary immersion system. Agricultura Técnica 62(1):68-78

De Feria Silva M, Chávez Milián M, Quiala Mendoza E, Jiménez González E (2003). Efecto de la densidad de inóculo y la frecuencia de inmersión en la propagación in vitro de Psidium guajava cv. Enana roja en sistemas de inmersión temporal. Biotecnología Vegetal 3(3):149-154

Driver J, Kuniyuki A (1984). In vitro propagation of Paradox Walnut rootstock. HortScience 18(4):506-509

Ducos JP, Lambot C, Pétiard V (2007). Bioreactors for coffee mass prop- agation by somatic embryogenesis. International Journal of Developmental Biology 1(1):1-12

Escalona M, Aragon CA, Capote I, Pina D, Ceja I, Rodríguez R, Debergh P (2007). Physiology of effects of temporary immersion bioreactor (TIB) on micropropagated plantlets. Acta horticulturae 748(748):95-101

Escalona M, Lorenzo JC, González B, Daquinta M, González JL, Desjardins Y, Borroto CG (1999). Pineapple (Ananas comosus L. Merr) micropropagation in temporary immersion systems. Plant Cell Reports 18:743-751

Georgiev V, Schumann A, Pavlov A, Bley T (2014). Review temporary immersion systems in plant biotechnology. Engineering Life Sciences 14(6):607-621

Herrera Herrera C. (2016) Evaluación de fuentes semilleras de especies forestales nativa, como apoyo a programas y políticas de reforestación de laprovincia de Loja. En: Herrera Herrera C (Ed.)., Evaluación de fuentes semilleras de especies forestales nativa, como apoyo a programas y políticas de reforestación de laprovincia de Loja (pág. 95). Loja, Ecuador

Long L, Preece J, Van Sambeek J (1995). Adventitious regeneration of Juglans nigra L. (eastern black walnut). Plant Cell Reports 14(12):799-803

Lopez Carvajal J, Piedrahita Cardona E (1998). Respuesta de la semilla de Cedro Negro (Juglans Neotropica Diels) a la aplicación de tratamientos pregerminativos. Revista Facultad Nacional de Agronomía, 51(1):217-235

Payghamzadeh K, Sayyed KK (2011). In vitro propagation of walnut - A review. African Journal of Biotechnology 10(3):290-311

Peña TD, Rocano CM, Salazar OJ, Torres C (2014). Inducción de la brotación in vitro de microplántulas de Nogal (Juglans neotropica) tratadas con Thidiazuron (TDZ) y 6 Bencilaminnopurina (BAP). MASKANA 5(2):81-85

Perrugoria M (2012). Desarrololo de una técnica para micropropagación de especies leñosas en biorreactores. Tesis de maestría, Facultad de Ciencias, Universidad de la República (Uruguay)

Quintero García O, Jaramillo Villegas S (2012). Rescate y germinación in vitro de embriones inmaduros de cedro negro (Juglans neotropica Diels). Acta Agronómica 61(1):52-60

Ramírez-Mosqueda MA, Iglesias-Andreu LG (2016). Evaluation of different temporary immersion systems (BIT®, BIG, and RITA®) in the micropropagation of Vanilla planifolia Jacks. In Vitro Cellular \& Developmental Biology-Plant 52(2):154-160 
Robert ML, Herrera-Herrera JL, Herrera-Herrera G, Herrera-Alamillo MA, Fuentes-Carrillo PA (2006). New temporary immersion bioreactor system for micropropagation. pp. 121-129. In: Loyola-Vargas VM, Vazquez-Flota F. (Eds.). Plant cell culture protocols ( $2^{\text {nd }}$ ed.), Vol. 11. Totowa, NL: Humana Press

Rojas Rodríguez F, Torres Córdova G (2008). Árboles del Valle Central de Costa Rica: reproducción. Kurú: Revista Forestal (Costa Rica) 6(17):1-3

Ross S, Castillo A (2010). Micropropagación de Achyrocline flaccida (Weinm.) DC. en medios de cultivo líquidos. Agrociencia XIV(1):1-71

Sánchez Zamora M, Cos Terrer J, Frutos Tomás D, García López R (2006). Embryo germination and proliferation in vitro of Juglans regia L. Scientia Horticulturae 108(3):317-321

Toosi S, Dilmagani K (2010). Proliferation of Juglans regia L. by in vitro embryo. Journal of Cell Biology and Genetics 1(1):12-19

Watt P (2012). The status of temporary immersion system (TIS) technology for plant micropropagation. African Journal of Biotechnology 11(76):1-11 